\title{
Validation of the Mental Toughness Measure of Athletes and Non-athletes with the Structural Equation Model
}

\author{
Issam Eddine Ben Chelbi ${ }^{1,2,3^{*}}$, Jaouad Alem ${ }^{4}$, Driss Boudhiba ${ }^{1,5}$ Sabeur Hamrouni ${ }^{1,3}$, Riadh \\ Khalifa ${ }^{1,6}$, and Sabri Gaied Chortane ${ }^{1,7}$ \\ ${ }^{1}$ High Institute of Sport and Physical Education of Ksar Saï, University of Manouba, Manouba, \\ Tunisia. \\ ${ }^{2}$ Research group on evaluation and development of physical activity and health skills (GREDDCAPS)' \\ Sudbury (Ontario), Canada. \\ ${ }^{3}$ Research Laboratory "Sports Performance Optimization" National Center of Medicine and Science \\ in Sports (CNMSS), Tunis, Tunisia. \\ ${ }^{4}$ School of Kinesiology and Health Sciences, Laurentian University, Sudbury (Ontario) Canada. \\ ${ }^{5}$ Clinical Psychology Laboratory Intersubjectivity and Culture. \\ ${ }^{6}$ Research Unit « Sport performance \& health». \\ ${ }^{7}$ Exercise Physiology and Physiopathology: from Integrated to Molecular «Biology, Medicine and \\ Health» (Code: LR19ES09).
}

\begin{abstract}
The use of structural equation models (SEM) in scientific research perform a promising methodological and empirical direction to validate the measurement of psychological constructs. The aim of this paper is to validate the measurement of mental toughness of athletes and non-athletes with SEM. The sample consisted of 853 Tunisian participants (444 males and 409 females; 409 athletes and 444 non-athletes), aged 14 to 27 years ( $M=20.38$ $\mathrm{SD}=4.12)$. The sample completed the Arabic translated questionnaire of Clough, Earle [1] which measures six components of their mental toughness. The SEM approved a good model fit $\left(\chi^{2}=1146.33 ;\right.$ df $\left.=1065 ; \mathrm{CFI}=.93 ; \mathrm{SRMR}=.063 ; \mathrm{RMSEA}=.009\right)$ which allows for a valid Arabic-speaking measure of the six components of mental toughness.
\end{abstract}

\section{Introduction}

Modelling represents a crucial vector for the development of scientific research. In particular, the use of structural equation models is an opportunity for researchers and an adequate solution to the design of theoretical models. These methods, which were developed in the

\footnotetext{
${ }^{*}$ Corresponding author: issameddinebenchelbi@ISSEPKS.u-manouba.tn
} 
1970 s of the 20th century [2], have become commonly adopted in empirical work. They are integrated into the framework of second generation multivariate analyses and constitute advanced methods for research [3, 4].

On the academic level, structural analyses contribute enormously to the development of theory and methodological approaches [5]. Thus, the contributions manifest themselves above all through the validation of multi-item measurement scales, the testing of linear Relations between the different elements of the model construction, the identification of mediating effects as well as the verification of moderating influences between the latent variables in question. Nevertheless, the use of these methods at the managerial level remains relatively restricted and much more limited.

To this effect, these methods are more advantageous compared to the various traditional methods of analysis (in particular simple and multiple regressions, simple correlation tests and canonical analyses) insofar as they allow the estimation of errors and the evaluation of the quality of the model's fit at the level of cross-sectional and longitudinal analyses [6-8]. Certainly, the development and use of specific software and data processing programs (notably LISREL, AMOS, EQS, SEPATH from STATISTICA and PLS from XLSTAT, etc.) has made the use of these methods increasingly practical and popular. Starting from the origins of psychometric theory, previous work has revealed that modelling by structural equations has been mainly derived from two traditional techniques, namely factor analysis and simultaneous equation models [9]. Consequently, these models have given rise to two complementary approaches, namely the analysis of covariance structures (CSA) of an explanatory nature, and partial least squares (PLS) of a predictive nature [10].

\subsection{The conceptual foundations of Structural Equation Modelling (SEM)}

In agreement with Hoyle [11], structural equation modelling represents "a comprehensive statistical approach to testing hypotheses about the relationships between observed and latent variables". Similarly, Kaplan [9], states that this approach represents "a set of techniques that allow hypotheses to be made about the means, variances and covariances of observed data as a function of a minimum number of 'structural' parameters determined by an underlying design". These multivariate methods are commonly adopted in social science research. They explicitly and clearly take into account measurement uncertainties when studying the relationship between variables, as well as having the exclusive right to incorporate latent (or not directly observable) variables into the model of interest.

As such, Hoyle [11], considers that latent variables form a set of constructs or theoretical or hypothetical dimensions of major importance in many sciences. They also represent variables that are unobservable at the level of samples of the population studied.Thus, a model of structural equations consists of a set of measurement indicators (also called manifest variables), latent variables and errors. Overt and latent variables can be independent or dependent, depending on their positions in the structural model. Similarly, the nature of the relationship between the measurement indicators and their latent variables determines whether the nature of the observed variables is reflexive or formative. Figure 1 below shows an example of a reflexive structure of a causal model. 


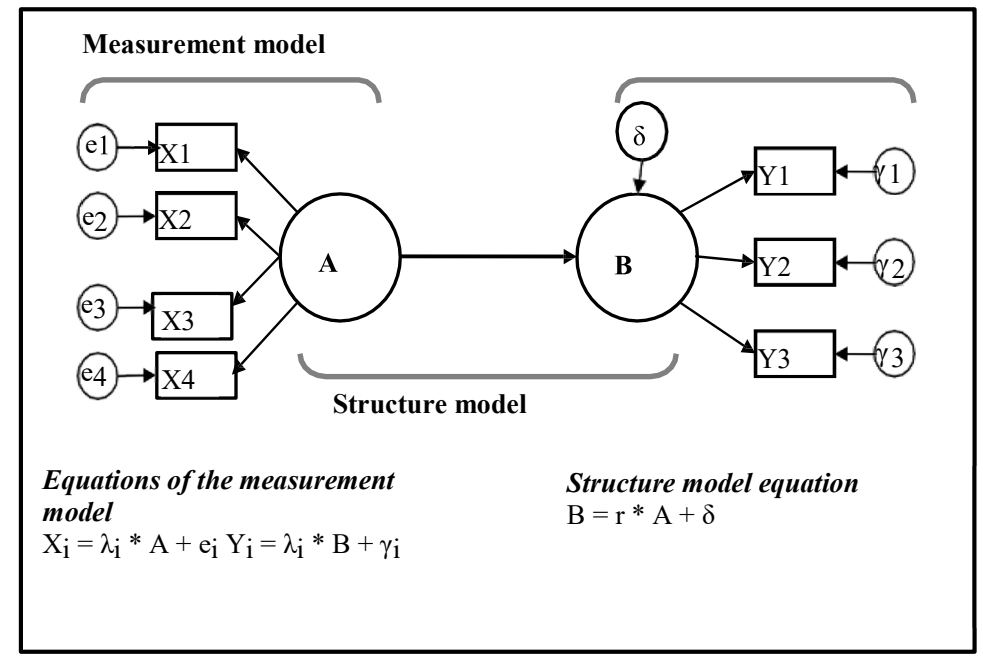

Fig. 1. Illustrative example of a causal model (reflective indicators)

As illustrated in Figure 1, the proposed causal model involves establishing a measurement model and a structural model. It also includes the set of independent observable variables (Xi), dependent observable variables (Yi), an explanatory latent variable (A), a latent variable to be explained (B) and error terms (ei, $\delta$ and $\gamma \mathrm{i}$ ). Therefore, it is possible to distinguish between two types of equations, namely the measurement model equations and the structure model equations.

In addition, there is a measurement model that clarifies the relationship between the observed and latent variables, and a structure model that examines the relationship between the different latent variables. The structural equation method is a true multivariate technique that associates the measurement and structural models while simultaneously examining a series of linear relationships between the observed and latent variables on the one hand, and between all the latent variables on the other [12].

\subsubsection{Model estimation}

The estimation process consists of establishing the relative values of the different parameters of the model undergoing investigation. There are several estimation methods in the literature. The choice of one of these methods depends on a number of conditions including the sample size and the distribution of data [13]. According to the work of Baumgartner and Homburg [5], Schumacker and Lomax [2] and Chaput [14], the Maximum Likelihood (ML) and Generalized Least Squares (GLS) estimation methods are the most common because they are included in most statistical computing applications.

\subsubsection{Evaluation of the model}

The quality of a model can be assessed through the evaluation of a set of adjustment indices. Each of these indices has a set of specific characteristics. Consequently, there are several adjustment indices which can be organised into three classes, namely absolute indices, incremental indices and parsimony indices.

Absolute indices are qualified as classical indices [14]. They are used to check the level of correspondence between the suggested model and the observed data [2]. In other words, these 
indices determine the resemblance or divergence between the estimated model and the observed variance/covariance matrix $[2,8]$.

Incremental indices make it possible to evaluate the contribution of the model under study in relation to a basic restrictive model [14]. Indeed, these indices allow a direct confrontation between the estimated model and the reference model with a zero correlation between the observed data [8].

The parsimony indices make it possible to control the overestimation of the model. They condition the required number of parameters to be estimated in order to obtain a precise degree of adjustment [2]. Indeed, the objective is to optimise the fit and minimise the number of estimated coefficients [8].

Thus, the following table illustrates the main indices adopted in marketing and their specificities, taking into account the work of Evrard, Pras [4], Russel, Durieu [8], and Schumacker and Lomax [2]. These indices must be in line with the tolerance levels commonly accepted by specialists to ensure a good fit of the model used

Table 1. Adjustment indices of the structural equation model

\begin{tabular}{|c|c|c|c|}
\hline $\begin{array}{l}\text { Types of } \\
\text { indices }\end{array}$ & Characteristics & Examples & $\begin{array}{l}\text { Empirical } \\
\text { acceptance } \\
\text { thresholds }\end{array}$ \\
\hline \multirow{5}{*}{$\begin{array}{l}\text { Absolute } \\
\text { indices }\end{array}$} & \multirow{5}{*}{$\begin{array}{l}\text { These indices make it possible to verify } \\
\text { the similarity between the theoretical } \\
\text { model and the observed data. }\end{array}$} & Khi-deux & - \\
\hline & & $\begin{array}{l}\text { GFI : Goodness of Fit } \\
\text { Index }\end{array}$ & \multirow{2}{*}{$\begin{array}{l}\text { Values greater } \\
\text { than } 0.9\end{array}$} \\
\hline & & $\begin{array}{l}\text { AGFI : Adjusted } \\
\text { Goodness of Fit Index }\end{array}$ & \\
\hline & & $\begin{array}{c}\mathrm{RMR}: \text { Root-mean-square } \\
\text { residual }\end{array}$ & \multirow{2}{*}{$\begin{array}{l}\text { Values less than } \\
0.05\end{array}$} \\
\hline & & $\begin{array}{l}\text { RMSEA : Root-mean- } \\
\text { square error of } \\
\text { approximation }\end{array}$ & \\
\hline \multirow{5}{*}{$\begin{array}{l}\text { The } \\
\text { indices } \\
\text { incremental }\end{array}$} & \multirow{5}{*}{$\begin{array}{l}\text { These indices make it possible to } \\
\text { compare the tested model with the } \\
\text { reference model. }\end{array}$} & $\begin{array}{l}\text { CFI : Comparative Fit } \\
\text { Index }\end{array}$ & \multirow{5}{*}{$\begin{array}{l}\text { Values greater } \\
\text { than } 0.9\end{array}$} \\
\hline & & NFI : Normal Fit Index & \\
\hline & & RFI : Relative Fit Index & \\
\hline & & IFI : Incremental fit Index & \\
\hline & & $\begin{array}{l}\text { TLC : Tucker-Lewis } \\
\text { Coefficient }\end{array}$ & \\
\hline $\begin{array}{l}\text { The } \\
\text { parsimony } \\
\text { indice }\end{array}$ & $\begin{array}{c}\text { This index makes it possible to obtain a } \\
\text { simpler model with a better fit. }\end{array}$ & $\begin{array}{l}\text { Khi- two standardised } \\
\quad(\text { Khi-deux/df })\end{array}$ & $\begin{array}{l}\text { Values less } \\
\text { than 2even } 3\end{array}$ \\
\hline
\end{tabular}

It should be noted from Table 1 that the adjustment indices are multiple compared to those of traditional methods (notably the regression method) and that the question of setting key 
values or acceptance thresholds for these indices has been the subject of some divergence between researchers.

\subsection{The specification of the model}

This new speciation of the model constitutes a form of reflection that allows the design of the model to be reconsidered and possible modifications suggested, taking into account the theoretical context of the research concerned [13]. Similarly, Russel, Durieu [8], stress that the model specification phase must be carried out carefully with a view to making possible improvements to the original model. For example, it would be possible to add or remove parameters, set or modify constraints, etc. while taking into consideration the bases of the theory on which the basic model design is based.

\subsection{The concept of mental toughness}

The supreme instrument to assess MT in sport and non-sport settings is the mental toughness questionnaire 48 [1]. The MTQ48 does not limit itself to assessing overall mental toughness, but its different sub-sectors in six $6 \mathrm{C}$ components, such as commitment, challenge, emotional and life control, confidence in abilities and interpersonal confidence. Gucciardi, Hanton [15] suggested the requirement for a more detailed psychometric study of the factor structure of the questionnaire. They studied 686 athletes and 639 full-time employees to verify four structural factors of the MTQ48. Answers were tested with the CFA (confirmatory factor analysis) and the ESEM (Exploratory structural equation modelling). Results did not corroborate the $4 \mathrm{C}$ or $6 \mathrm{C}$ factor model. Gucciardi, Hanton [15] pointed to the need for a more in-depth study with a larger sample. In addition, another paper in response to the study by Gucciardi, Hanton [15] argued that the study had not been subjected to an extensive review of the literature, was unaware of the limitations of CFA, and selected the wrong sample [16]. The progress of the MTQ48 resulted in the MT Model 6C. Earle [17] stated that TM is best explained when the concepts of control and confidence are separated into two nested components. In particular, Earle [17] has realized interrogations with many athletes to explore the composition of MT. Although the results revealed that the majority of the models could be categorized according to the concept of Kobasa [18]'s model of confidence, Earle [17] suggested that control and confidence have a more complicated construction, with control (control - emotion, control - life) and confidence (confidence - ability, confidence relational) having two complementary dimensions. This approach has resulted in the creation of the 6 Cs model of MT. Despite MTQ48's wide application has been the subject of some criticism [19], the results of the analyses did not corroborate the principle of the four- and six-factor approach, although Gucciardi, Hanton [15] insisted on the necessity to re-examine the MTQ48 with a broader membership. In addition, a recent statement in response to his article noted that he did not have a complete review of the literature, did not recognize the shortcomings of the confirmatory factor analysis CFA, and used irrelevant samples. The 48item instrument was intended to assess mental toughness [16]. These tools were used to test the impact of psychological intervention on mental toughness. Even though specialists have demonstrated the credibility and reliability of the MTQ48 [20], the supporting evidence for the development program is too weak and Clough, Earle [1] do not specify the details of the procedures used to establish the items and the corresponding inventory (i.e. exploratory and confirmatory factor analysis techniques). Theoretical constraints are also related to the context of many MTQ items 48. Through the confidence subscale, for example, one finds various items whose theme is not compatible with the description of the scale. Questions such as "I generally feel useful" and "I sometimes feel completely useless" tend to capture notions of self-esteem [21], and not the "high sense of self-confidence" he's supposed to have. Similar 
factors appear to be more closely related to the presence of a positive view of the same issue [22].

\subsection{Objective of this study}

The objective of this study was to assess the factor validity of the Arabic version of the MTQ48 Mental Toughness Questionnaire, in order to gain insight into the status of the currently well-used but unfounded measure of mental toughness. To increase the social impact of the measurement tool, we chose to administer it to a large sample of subjects $(\mathrm{N}=853)$ that includes both genders and both state of participants (male versus female; athletes versus non-athletes), thus verifying that the measurement tool does not penalize any particular gender or status. The following section presents the chosen method and in particular the nature of the sample.

\section{Methods}

\subsection{Participants}

It was planned to ask candidates to submit demographic data, such as age, gender, whether they practice any sport and in which sports category they primarily practice. The sample comprises 853 Tunisian participants (444 males and 409 females; 409 athletes and 444 nonathletes), aged 14-27 years $(M=20.38 ; S D=4.12)$. During September 2019, participants reviewed and signed a consent form approved by the Institutional Review Committee before taking part in the current study.

\subsection{Measure}

The MTQ48 (Mental Toughness Questionniare-48) was conceptualized by [1], it is a 48 items inventory, which presents questions to be answered on a 5-point Likert scale ranging from (1) strongly disagree to (5) strongly agree. The steps for translating MTCQ48 are presented in the 'PROCEDURES for the Arabic translation of the MTQ48's section. In the initial version of the publication [1], the MTQ48 allows the measurement of six distinct sub-scales : challenge is defended by "8 items", commitment by "11 items", control - emotion by "7 items", control - life by "7 items", confidence - abilities by "9 items" and confidence interpersonal by "6 items". The ratings relate to: (1) Challenge, which determines the extent to which individuals perceive difficulties as sources of individual development and thrive in complex situations. (2) Commitment, which shows that one is extremely committed to what one is doing and is willing to persevere despite constraints or obstacles (3) Emotional Control, which is characterized by a desire to control one's anxieties and to be less inclined to show one's emotions to others. (4) Control over life, which is a belief in personal influence as opposed to powerlessness. (5) Confidence in ability, which reflects a desire to be more optimistic and less dependent on foreign approval, and (6) Interpersonal confidence, which suggests that individuals are more confident and less susceptible to threats in their environment. 


\section{Result}

\subsection{Structural equation model SEM of the MTQ48}

The model presented in (Figure 2) schematically, represents the SEM of MTQ48, and provides the mechanism by which it can be tested statistically. Results of the SEM are presented in (figure 2) containing the factor loadings of the six components models.

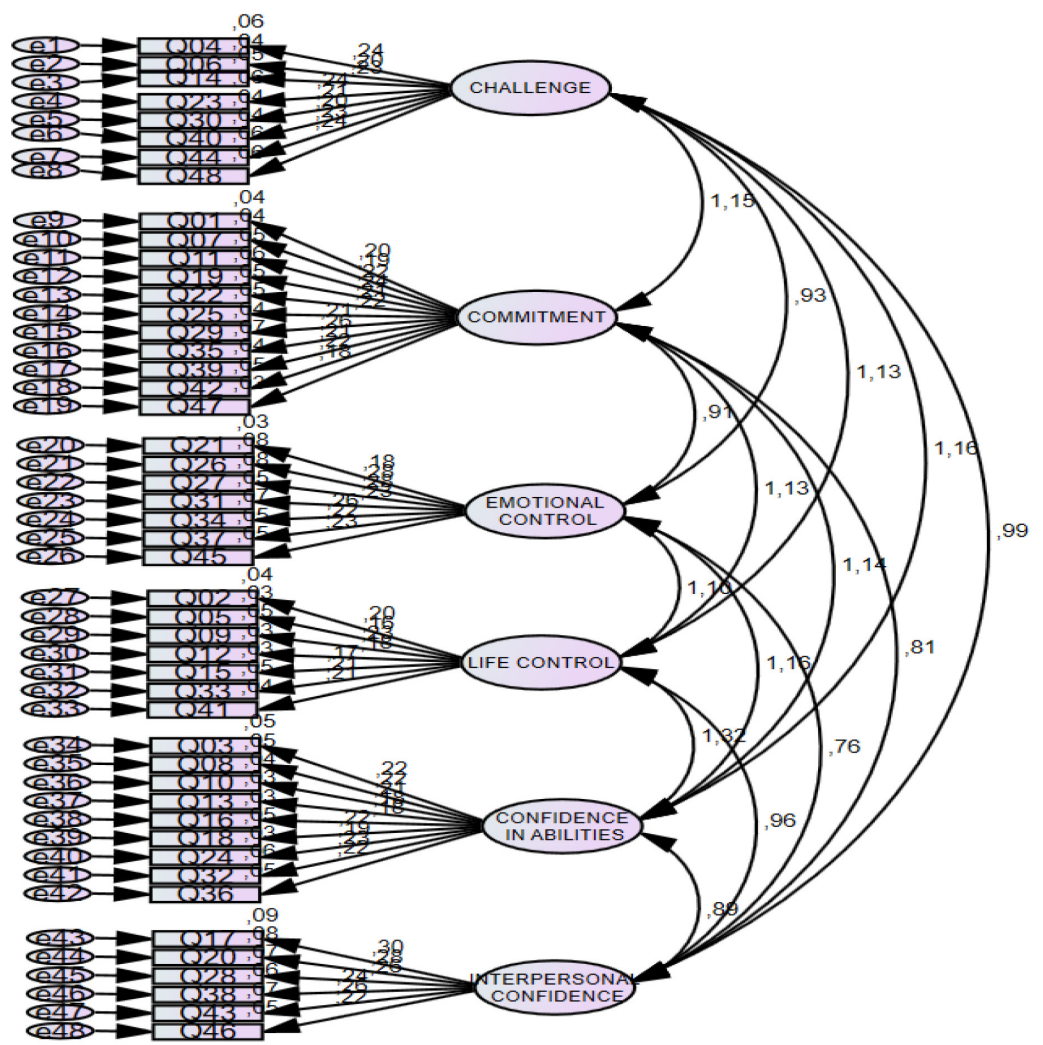

Fig. 2. The SEM model of the Arabic version of MTQ48: the six components of the mental toughness

Table 2 shows that there are several adjustment indices that can be used to assess whether a model fits the data in the sample properly. In most studies, at least the following five adjustment indices are found: chi-square $\chi^{2}$, CFI, TLI, SRMR and RMSEA. The CFI (comparative fit index) is not influenced by sample size. It estimates the improvement in the goodness of fit of the model compared to the independence model. A good fit is indicated by a value greater than 0.90 [23, 24]. For the TLI (Tucker-Lewis Index, 1973), a value of 0.95 indicates a good fit of the model[25]. For the SRMR (standardized mean square residual), a value below 0.05 implies a good fit of the model $[23,26]$. Finally, the RMSEA (root means square error of approximation) corrects for the tendency of chi-square to reject the model. A value smaller than 0.08 indicates an acceptable fit, a value below 0.05 indicates a very good fit, and a value below 0.01 shows an excellent fit of the model [26, 27]. SEM analysis supported the 6-factor solution as the best, representing good model fit $\left(\chi^{2}=1146.332\right.$, $d f=1065, \mathrm{CFI}=.927, \mathrm{SRMR}=.063$, RMSEA $=.009$ ).

Table 2. Model fit of SEM 


\begin{tabular}{|c|c|c|c|}
\hline Measure & Description & $\begin{array}{c}\text { The level for } \\
\text { a good fit }\end{array}$ & six factor \\
\hline$\chi^{2}$ & chi-square & -- & 1146.332 \\
\hline Df & degrees of freedom & -- & 1065 \\
\hline$\chi^{2} / \mathrm{df}$ & The discrepancy divided by degrees of freedom & Less than 5 & 1.076 \\
\hline$(\mathrm{A}) \mathrm{GFI}$ & (Adjusted) Goodness of Fit & AGFI $\geq .90$ & .942 \\
\hline CFI & comparative fit index & CFI $\geq .90$ & .927 \\
\hline TLI & Tucker-Lewis index & TLI $\geq .95$ & .922 \\
\hline SRMR & standardized root-mean-square residual & SRMR $<.08$ & .063 \\
\hline RMSEA & root mean square error of approximation & RMSEA $<.08$ & .009 \\
\hline
\end{tabular}

\section{Discussion}

The objective of this study was to validate the Arabic version of Mental Toughness Questionnaire (MTQ48) in order to gain insight into the status of the currently well-used but measure of mental toughness(clough et al.(2002); 6 components). Based on the SEM assessment indices, the conceptual validity of the six-factor mental toughness questionnaire introduced by [1] was endorsed. The sample consisted of 853 Tunisian participants (444 males and 409 females; 409 athletes and 444 non-athletes), aged 14-27 years $(M=20.38 S D=4.12)$. Cronbach's alpha suggests that 48 items has adequate internal consistency $\left(\alpha_{M T}=.72\right)$. From an eigenvalue greater than 1 , the factors in this questionnaire were found to be $21.19 \%$ of the total variation. The exploratory factor analysis (EFA), using principal component analysis (PCA) with the PROMAX rotation method, showed good sampling quality by the Kaiser-Meyer-Olkin index $(\mathrm{KMO}=.709)$ and Bartlett's sphericity index of $(\mathrm{df}=1128 ; \mathrm{p}<.001)$, indicating that the EFA is appropriate. Pearson's correlation revealed a significant (from moderate to weak) correlation between the Clough et al. (2002) conceptual factors and the obtained factors. Confirmatory factor analysis (SEM) applied on AMOS software approved an acceptable statistical fit of the translated version $\left(\chi^{2}=1146.332, \mathrm{df}=1065, \mathrm{CFI}=.927, \mathrm{SRMR}=.063\right.$, RMSEA=.009).

Clough, Earle [1] has evolved the MTQ48 to be able to determine the factors considered measures of mental toughness, as described in the conceptual model of the $4 \mathrm{Cs}$ they propose. These factors have excellent apparent legitimacy and are considered convincing from a theoretical standpoint [20]. Yet the verification of the factor structure in this research, using confirmatory factor analyses, showed good agreement with the data and appropriate solutions.

The SEM results demonstrated that the six-factor model produced acceptable results that were more consistent with the data proposed in the literature [28]. Although MTQ48 has already been measured in sport and non-sport standard samples, this analysis is among the first to highlight the extent of the levels of expertise. Studies have shown that professional athletes generally obtain better rankings than amateur athletes [29] and nonathletes [30], the latter point indicating that professional athletes have the power to understand the elements of the MTQ48 differently than non-athletes. Compared to past psychometric research, the current results are positive in terms of the degree of specification. Birch, Crampton [31], Gucciardi, Hanton [15] and Perry, Nicholls [32] respondents reported ineligible rates of adjustment errors and significant wording errors 
in their results, while this survey found reasonably acceptable rates of wording errors in the SEM setting. Psychometric assessment must be founded on both empirical and conceptual observations [33]. In addition, MTQ48 is a universal measure of MT since Clough, Earle [1], Gucciardi and Gordon [34] established a psychometrically robust measure of MT.

Current interpretations call for caution with respect to the use of MTQ48 with populations of athletes. However, it is difficult to reach an agreement and make progress with the MTQ48 because of the multimodal framework presented by Clough, Earle [1], i.e. competing one-, four- and six-factor variants. Although there is a great deal of research confirming the trustworthiness of the scale, but less validity, it is evident that the questionnaire assesses certain elements of consistent custom $[22,35,36]$. On the other hand, what it evaluates seems theoretically vast $[15,28,31]$. Therefore, further concrete information is needed to clarify and justify the operationalization of MT by Clough, Earle [1]. Moreover, this innovative research does not devalue the properties of the balance psychometrically, but asks Clough and his colleagues to justify a way forward for further studies using the four- or six-factor formulas. This will allow the MT specialists to build a consistent body of data based on the very conceptual structure that will promote the progress and strengthening of MT research. Until then, specialists must carefully analyse the observations made by the MTQ48 on examples of professional athletes, since the factor structure is similar to the six-factor principle in non-athletes, yet is slightly less conclusive in high-level sportspeople and amateurs. One of the strengths of conducting the above surveys is the size and scope of the study population, which provides a full range of opportunities for the expression of MT in the sport context. Nevertheless, the results of this analysis still need to be evaluated with several caveats. To start with, the thresholds used for the adjustment indices in the SEM procedures were recommended without any specific index having been constructed. Secondly, the sample size of elite athletes may have been inappropriate for SEM, and future studies should seek to enhance the composition of this population or establish comparative tests to determine what can be considered acceptable within the MTQ48 and other dimensions. Despite the impressive amount of research on mental toughness identified in this study, its definition, conceptualization and measurement are still debated. There seems to be general agreement that mental toughness is a multidimensional component that enables subjects to cope with the challenges, pressures and barriers they face. The exact composition, definition and conceptualization of this concept, however, remains very confusing due to the unique way in which existing studies [1, 15, 37]. As the fundamentals of the empirical and theoretical underpinnings of mental toughness develop, there are different conceptualizations, across sports disciplines (Jones et al., 2002, 2007) [34, 38], which just blurs the theoretical data that's otherwise obscure. Whatever progress has been made, a number of shared constraints have been imposed, in particular because of reductive procedures that lack rigour and are more informative and explanatory in nature than scientifically rigid criteria $[1,39]$. The crucial point is that experts are working to develop a common definition and conceptualization of mental toughness and to specify the relationships between the multiple form and its components. This will help to promote mental resilience as a model and not merely as a set of associated factors; while at the same time helping to develop the positive implications of making this model a reality.

\section{Conclusion}

We were able to conclude from this research work that the use of the structural equation method has reached a level of maturity allowing the development of the theory, thanks to a 
rigorous approach, and a set of advanced techniques that allow the generation of precise and relevant results. Indeed, the notion of latent variables, the resolution of systems of simultaneous equations, the taking into account of measurement errors and the validation of multi-item scales etc., all aim at making this method more efficient and powerful. For this reason, the debate on the results usually leads to the formulation of rich and in-depth information, with the aim of proposing a series of theoretical and operational solutions.

\section{References:}

1. Clough, P., K. Earle, and D. Sewell, Mental toughness: The concept and its measurement. Solutions in sport psychology, 2002: p. 32-43.

2. Schumacker, R.E. and R.G. Lomax, A beginner's guide to structural equation modeling. 2004: psychology press.

3. Valette-Florence, P., Spécificités et apports des méthodes d'analyse multivariée de la deuxième génération. Recherche et Applications en Marketing (French Edition), 1988. 3(4): p. 23-56.

4. Evrard, Y., B. Pras, and E. Roux, Market: Études et recherches en marketing (3 e ed.). Paris: Dunod, 2003.

5. Baumgartner, H. and C. Homburg, Applications of structural equation modeling in marketing and consumer research: A review. International journal of Research in Marketing, 1996. 13(2): p. 139-161.

6. Hulland, J., Y.H. Chow, and S. Lam, Use of causal models in marketing research: A review. International journal of research in marketing, 1996. 13(2): p. 181-197.

7. Steenkamp, J.-B.E. and H. Baumgartner, On the use of structural equation models for marketing modeling. International journal of research in marketing, 2000. 17(23): p. 195-202.

8. Russel, P., et al., Méthodes d'équations structurelles: recherches et application en gestion. Economica, Paris, 2002.

9. Kaplan, D., Structural equation modeling: Foundations and extensions. Vol. 10. 2008: Sage Publications.

10. Croutsche, J.-J., Étude des relations de causalité: Utilisation des modèles d'équations structurelles (approche méthodologique). La Revue des Sciences de Gestion: Direction et Gestion, 2002(198): p. 81.

11. Hoyle, R.H., Structural equation modeling: Concepts, issues, and applications. 1995: Sage.

12. Hair, J.F., et al., Multivariate Data Analysis: Pearson Prentice Hall. Upper Saddle River, NJ, 2006: p. 1-816.

13. Chin, W.W., R.A. Peterson, and S.P. Brown, Structural equation modeling in marketing: Some practical reminders. Journal of marketing theory and practice, 2008. 16(4): p. 287-298.

14. Chaput, L., Modèles contemporains en gestion: un nouveau paradigme, la performance. 2007: PUQ.

15. Gucciardi, D.F., S. Hanton, and C.J. Mallett, Progressing measurement in mental toughness: A case example of the Mental Toughness Questionnaire 48. Sport, Exercise, and Performance Psychology, 2012. 1(3): p. 194.

16. Clough, P., et al., Comment on "Progressing measurement in mental toughness: A case example of the Mental Toughness Questionnaire 48” by Gucciardi, Hanton, and Mallett (2012). 2012.

17. Earle, K., The construct of mental toughness: A psychometric and experimental analysis. 2007, University of Hull. 
18. Kobasa, S.C., Stressful life events, personality, and health: an inquiry into hardiness. Journal of personality and social psychology, 1979. 37(1): p. 1.

19. Connaughton, D., et al., Mental toughness research: Key issues in this area. International Journal of Sport Psychology, 2008. 39(3): p. 192-204.

20. Crust, L., A review and conceptual re-examination of mental toughness: Implications for future researchers. Personality and individual differences, 2008. 45(7): p. 576-583.

21. Harter, S., The perceived competence scale for children. Child development, 1982: p. 87-97.

22. Crust, L. and C. Swann, Comparing two measures of mental toughness. Personality and Individual Differences, 2011. 50(2): p. 217-221.

23. Hu, L.t. and P.M. Bentler, Cutoff criteria for fit indexes in covariance structure analysis: Conventional criteria versus new alternatives. Structural equation modeling: a multidisciplinary journal, 1999. 6(1): p. 1-55.

24. Kline, R.B., Convergence of structural equation modeling and multilevel modeling. 2011, na.

25. Tucker, L.R. and C. Lewis, A reliability coefficient for maximum likelihood factor analysis. Psychometrika, 1973. 38(1): p. 1-10.

26. Byrne, B.M., Structural equation modeling with AMOS: basic concepts, applications, and programming (multivariate applications series). New York: Taylor \& Francis Group, 2010. 396: p. 7384.

27. Jöreskog, K.G. and D. Sörbom, LISREL 8: User's reference guide. 1996: Scientific Software International.

28. Perry, J.L., et al., Factorial validity of the mental toughness questionnaire-48. Personality and individual differences, 2013. 54(5): p. 587-592.

29. Golby, J. and M. Sheard, Mental toughness and hardiness at different levels of rugby league. Personality and individual differences, 2004. 37(5): p. 933-942.

30. Gerber, M., et al., Adolescents' exercise and physical activity are associated with mental toughness. Mental health and physical activity, 2012. 5(1): p. 35-42.

31. Birch, P., et al., The Mental Toughness Questionniare-48: A Re-examination of Factorial Validity. International journal of sport psychology, 2016. 48.

32. Perry, J.L., et al., Assessing model fit: Caveats and recommendations for confirmatory factor analysis and exploratory structural equation modeling. Measurement in physical education and exercise science, 2015. 19(1): p. 12-21.

33. Hopwood, C.J. and M.B. Donnellan, How should the internal structure of personality inventories be evaluated? Personality and Social Psychology Review, 2010. 14(3): p. 332-346.

34. Gucciardi, D.F. and S. Gordon, Development and preliminary validation of the Cricket Mental Toughness Inventory (CMTI). Journal of Sports Sciences, 2009. 27(12): p. 1293-1310.

35. Clough, P. and D. Strycharczyk, Developing mental toughness: improving performance, wellbeing and positive behaviour in others. 2012: Kogan Page Publishers.

36. Crust, L. and P.J. Clough, Relationship between mental toughness and physical endurance. Perceptual and motor skills, 2005. 100(1): p. 192-194.

37. Jones, G., S. Hanton, and D. Connaughton, A Framework of Mental Toughness in the World's Best Performers. 2007. 21(2): p. 243.

38. Bull, S.J., et al., Towards an understanding of mental toughness in elite English cricketers. Journal of applied sport psychology, 2005. 17(3): p. 209-227.

39. Loehr, J., The new toughness training for sports: Mental, emotional, and physical conditioning. Nueva York: A Plume Book, 1995. 